City University of New York (CUNY)

CUNY Academic Works

2015

\title{
Education and Marriage Decisions of Japanese Women and the Role of the Equal Employment Opportunity Act
}

Linda N. Edwards

CUNY Graduate Center

Takuya Hasebe

Sophia University

Tadashi Sakai

Hosei University

Follow this and additional works at: https://academicworks.cuny.edu/gc_econ_wp

Part of the Economics Commons How does access to this work benefit you? Let us know!

More information about this work at: https://academicworks.cuny.edu/gc_econ_wp/8

Discover additional works at: https://academicworks.cuny.edu

This work is made publicly available by the City University of New York (CUNY).

Contact: AcademicWorks@cuny.edu 
CUny Graduate Center Ph.D Program in Economics WORKING PAPER SERIES

\title{
Education and Marriage Decisions of Japanese Women and the Role of the Equal Employment Opportunity Act
}

\author{
Linda N. Edwards \\ Takuya Hasebe \\ Tadashi Sakai \\ Working Paper 7 \\ Ph.D. Program in Economics \\ CUNY Graduate Center \\ 365 Fifth Avenue \\ New York, NY 10016 \\ September 2015
}

We are grateful to the Institute for Research on Household Economics for permitting us to use the Japanese Panel Survey of Consumers for this research. We thank participants in seminars at the CUNY Graduate Center, the Japanese Economic Association, and the Western Economic Association International, Yukiko Abe, and especially Cordelia Reimers, for helpful comments. We also thank Kaori Shiba for her excellent research assistance. This paper is a revised version of a paper presented at the June 29-July 3, 2012, meetings of the Western Economic Association International.

(C) 2015 by Linda Edwards, Takua Hasebe, and Tadashi Sakai. All rights reserved. Short sections of text, not to exceed two paragraphs, may be quoted without explicit permission provided that full credit, including $@$ notice, is given to the source. 
Education and Marriage Decisions of Japanese Women and the Role of the Equal Employment Opportunity Act Linda N. Edwards, Takuya Hasebe, and Tadashi Sakai JEL No: J12, J24, I21, K31

\begin{abstract}
Prompted by concordant upward trends in both the university advancement rate and the unmarried rate for Japanese women, this paper investigates whether the Equal Employment Opportunity Act (EEOA), which was passed in 1985, affected women's marriage decisions either directly or via their decisions to pursue university education. To this end, we estimate a model that treats education and marriage decisions as jointly determined using longitudinal data for Japanese women. We find little evidence that the passage of EEOA increased the proportion of women who advance to university, but strong support for the proposition that it increased the deterrent effect of university education on marriage.
\end{abstract}

Linda N. Edwards

Ph.D. Program in Economics

City University of New York Graduate Center

365 Fifth Avenue

New York, NY 10016

ledwards@gc.cuny.edu

Takuya Hasebe

Dept. of Social Sciences

Sophia University

Tokyo, Japan

thasebe@sophia.ac.jp

Tadashi Sakai

Department of Economics

Hosei University

Tokyo, Japan

t.sakai@hosei.ac.jp 


\section{Introduction}

The striking decline in Japanese birth rates over past thirty years has prompted national concern, with fertility rates well below the population replacement rate (Faruqee and Mühleisen 2001; Japan Ministry of Health, Labour and Welfare 2015). ${ }^{1}$ The resulting shrinking population means that in the future, the country's old-age dependency ratio will increase as the large postwar baby boom and baby boom echo cohorts are supported by subsequent, smaller cohorts. ${ }^{2}$ Coincident with this decline in birth rates have been a decline in marriage rates (Sakamoto and Kitamura 2008) and a rise in the mean age of first marriage (Japan Ministry of Health, Labour and Welfare 2015), both of which are linked directly by fertility researchers to the decline in birth rates. ${ }^{3}$ Over the same period, with the passage of the Equal Employment Opportunity Act (EEOA) in 1985 and subsequent supporting legislation, career opportunities available to women have expanded, especially for women with a university education. ${ }^{4}$

\footnotetext{
${ }^{1}$ The total fertility rate reached its lowest point, at 1.26 , in 2005 and though it has risen in 2014 to 1.42 , it is still well below the population replacement rate (Japan Ministry of Health, Labour and Welfare 2015).

${ }^{2}$ The ratio of those aged 65 and above to the working-age population (aged 20-64 years) is estimated to rise from $27 \%$ in 2000 to $47 \%$ in 2025 , higher than estimated for other low-birth-rate counties like France and Italy (Faruqee and Mühleisen 2001, Table 1).

${ }^{3}$ As many researchers have noted (e.g. Hashimoto and Kondo, 2012), because the average number of children borne by a married couple has stayed relatively constant since the 1970 and the percent of births that take place outside of marriage is very small (less than $2 \%$ in 2003), it is the decline in the marriage rate of women that accounts for the overall declines in fertility. See also Narayan and Peng (2007). For a general review of models of marriage and childbirth see Ermisch (2003) and Brien and Sheran (2003).

${ }^{4}$ For a good review (in English) of the 1985 EEOA as well as the 1997 legislation (that went into effect in 1999) that substantially strengthened the original law, see Araki (1998). Yamada (2013) also summarizes these two laws and also provides a description of the subsequent 2006 law, which further expands on the original EEOA. In earlier literature the EEOA was referred to as the Equal Employment Opportunity Law, or EEOL, as opposed to the Equal Employment Opportunity Act, but EEOA is a more apt translation of the Japanese title for this law. With regard to legislation covering leaves for child and elder care, Japan Ministry of Health, Labour and Welfare (2010) is a good reference.
} 
The goal of this paper is to investigate the possible role the passage of the Equal Employment Opportunity Act in explaining the delay and decline in women's marriage, both directly and through the link of higher education. Existing literature has documented the increased proportion of women who get a university education over this period and suggested that the EEOA may have played a role in this increase (Edwards and Pasquale 2003, Abe 2011). At the same time, the large economic and demographic literature on the determinants of women's marriage propensity and timing underscores the role of educational attainment in marriage decisions, with university-educated women more likely than others to delay marriage (e.g. Raymo 2003). To our knowledge, only one paper (Abe 2011) addresses the possibility that the passage of the EEOA could be a factor in women's marriage decisions, but that paper does not explicitly test this proposition. In our paper, we address this void by investigating whether the EEOA affected women's marriage decisions either directly or via their decisions to pursue university education. Our model treats education and marriage decisions as jointly determined-something that has not been done in previous research on Japanese women - and is estimated using data from the Japanese Panel Survey on Consumers (JPSC).

Focusing on the likelihood that women marry by age 32 , our research provides strong support for the proposition that the passage of the EEOA played a role in the delay and decline of marriage. Specifically, even when we take explicit account of the effect of unmeasured personal attributes on education and marriage decisions, we find that the deterrent effect of university education on marriage more than doubles for post-EEOA cohorts of women, as compared to preEEOA cohorts. University-educated women in post-EEOA cohorts are 16 to 19 percentage points less likely than their less educated contemporaries to be married by age 32 , whereas for pre-EEOA cohorts the corresponding decline is at most 7 to 8 percentage points. On the other 
hand, we find that the decision to obtain a university education is primarily determined by a young woman's ability and a host of family background characteristic, with the EEOA having an ambiguous and at best small impact. Overall, our findings indicate that for those seeking to understand the declines over the past 30 years in marriage and fertility in Japan, it is important to take into account the role played by the EEOA.

In the sections below, we review selected recent research on the relationships among education, marriage, and the EEOA; sketch out a model of joint decision making with regard to education and marriage; describe the JPSC data; and provide estimates of our model using a recursive bivariate probit statistical methodology. A final section summarizes our conclusions and suggests some implications.

\section{Background and Related Research}

The trends that prompt our research and that of many others are illustrated in Figure 1. Shown in this figure are data from 1970 to 2013 for the total fertility rate, the percent of women aged 30-34 not married, the percent of female high school graduates who advance to university, and, for comparison, the percent of male high school graduates who advance to university. Throughout this period there has been a dramatic decline in the total fertility rate which, while increasing slightly since its nadir in 2005 , still remains well below the replacement rate. At the same time, the percent of women aged 30-34 who remain unmarried has steadily increased, from under $10 \%$ in 1970 to almost $35 \%$ in $2010 .^{5}$ Roughly parallel with this rise in the proportion unmarried is the increase in young women's advancement rate to university, growing from under

\footnotetext{
${ }^{5}$ Young women's mean age at first marriage has also been increasing over this period, from 24.2 in 1970 , to 28.8 in 2010, to 29.3 in 2013 (Japan Ministry of Health, Labour and Welfare 2015).
} 
$10 \%$ in 1970 to over $45 \%$ in 2010 . It is noticeable that the slopes of both of the latter two growth curves become steeper after 1985, the year in which the EEOA was enacted by the Japanese Diet. The advancement rate to university of young men also increased over the entire period, though less uniformly than that of women, but the difference between the advancement rates of men and women shrinks noticeably after 1985 .

These concordant trends suggest the following set of hypotheses, which we investigate in this paper: (1) The passage of the EEOA, by expanding career opportunities of universityeducated women, increased the proportion of qualified women who follow this educational path; (2) The expanded career opportunities associated with university education influence women's marriage decisions, leading them to delay or decline marriage; (3) The passage of the EEOA (and subsequent supporting legislation), which changed the legal and cultural landscape to make a career path more socially and economically attractive to women, increased the "deterrent" effect of university education on marriage.

To explore these hypotheses, we develop and estimate a multivariate model of the interrelationship between Japanese women's education and marriage decisions and the role of the EEOA in these decisions. ${ }^{6}$ No other studies directly address this set of hypotheses, but there are a number which examine some of the relevant relationships. Below we review the studies that most directly inform our research.

\footnotetext{
${ }^{6}$ Models like the one we use in this paper owe a great debt to the seminal work of Gary Becker on human capital, marriage, and the economics of the family (see, for example, Becker, 1976 and 1993).
} 


\section{The EEOA/Labor Market Link}

The hypotheses we explore are based on the assumption that the EEOA expanded career opportunities for university-educated women. Three recent papers, Abe (2011), (2010), and (2013), investigate this assumption by looking at effects of the EEOA on women's employment and earnings. The findings in these three studies, described in more detail below, indicate that the primary strategies used by post-EEOA cohorts of women to improve their career and labor market outcomes are to become university graduates, to work full-time (as opposed to part-time), and to delay or decline marriage.

Abe (2011) looks at women's labor force behavior over the life cycle using data from the Japanese Employment Status Survey (ESS, Shugyo Kozo Kihon Chosa) from 1998 to 2007. She explores how the EEOA affected women's full- and part-time employment patterns both by marital status and by level of educational attainment. Her methodology relies on comparing cohorts of women who entered the labor market after the EEOA went into effect with earlier, pre-EEOA, cohorts. Abe reports that the overall employment/population ratio of women has increased for more recent cohorts of women, but that when one distinguishes between part-time work and full-time "regular" employment, most of this overall increase is accounted for by an increase in part-time work. When the focus is narrowed to women's employment in full-time, regular positions-- the kinds of positions that were expected to be more available to women after the passage of the EEOA-- and after roughly taking into account macro-economic conditions, Abe finds that only for university graduates did this employment rate increase for post-EEOA cohorts. 
Taking this analysis further, Abe decomposes changes in full-time employment by marital status and finds that it was not that the full-time employment rate increased for both married and unmarried university-educated women, but rather that the proportion of these highly educated women who remained unmarried had increased. Pulling together these threads, we have a story in which in the post-EEOA period, women with a university education were delaying marriage (some perhaps choosing not to marry) and, since unmarried women have higher full-time employment rates than do married women, this delay translated to a higher fulltime employment rate of university women as a group. Abe's findings are based on a model that does not allow for the explicit possibility that marriage rates and educational attainment are themselves affected by the EEOA, but she recognizes these links in her conclusion: "Since the enactment of the EEOA, more women with university education have married late or stayed unmarried" (p. 52).

Abe (2010) targets the gender wage gap in Japan, rather than employment, and seeks to determine the impact of the EEOA using cohort data from the Basic Survey of Wage Structure at five-year intervals beginning with 1975 and ending with 2005. Focusing on full-time workers only, she shows that while the overall female/male full-time wage ratio increases over this period, this shift is mainly attributable to an increase in the educational attainment of the full-time female labor force. For university-educated women, the female-to-male wage gap narrowed very little for post-EEOA cohorts.

Abe (2013) is a survey paper which summarizes the result above, but also reports on research that explores the possibility that the EEOA may have had different impacts across the various Japanese regions. With regard to the latter topic, she concludes that such differences do exist: the post-EEOA increase in employment rates of university-educated women that she had 
documented in earlier research was most evident in the Tokyo area, most likely because that is where there is the greatest availability of managerial positions.

Taken together, these studies suggest that the benefits to Japanese women of the career opportunities enabled by the EEOA were to be obtained mainly by investing in university education and working (especially in Tokyo) a full-time schedule, the latter of which is facilitated by delaying or declining marriage. Abe (2013) comments that “...the EEOA did not increase the number of women who achieve both family and career..." (p. 32), positing that the scarcity of childcare and the costliness of commuting were likely obstacles.

\section{Higher Education and the EEOA}

The role of the EEOA law in young women's decisions with regard to post-high-school education is addressed in Edwards and Pasquale (2003). Using micro-data from the first wave of the Japanese Panel Survey on Consumers (JPSC), Edwards and Pasquale's analysis holds constant family background, demographic factors, and economic conditions in estimating the effect of the passage of the EEOA on the higher education decisions of young Japanese women. Their model does a good job of explaining higher education decisions, but the results with regard to the effect of the EEOA are not robust, in part because only two cohorts in the survey had made educational decisions after the passage of the law. Nonetheless, their research provides suggestive evidence that the passage of the law was associated with an increased propensity of young women to choose university education over junior college.

\section{Marriage}

There is an extensive economic and demographic literature on women's marriage rates in Japan, much of it focusing on explaining the secular declines illustrated in Figure 1. To our 
knowledge, none of this literature explicitly addresses the possible role of the EEOA in contributing to this decline, but a variety of other explanations have been explored. Some studies focus on the role of labor market conditions, including unemployment rates of men, women, or both (e.g. Higuchi 2001, Miyoshi 2014, and Hashimoto and Kondo 2012). Other studies focus on the role of the women's own earnings and income (e.g. Higuchi 2001, and Sakai 2009). Still others focus on the increasing levels of women's educational attainment and the resulting reduced relative availability of potential spouses with the requisite level of educationdubbed the "marriage mismatch" hypothesis (e.g. Raymo 2003 and Raymo and Iwasawa 2005). Other studies target increased income or other transfers (housing, for example) from parents to daughters as a potential explanation-- dubbed the "parasite single" hypothesis (Sakamoto and Kitamura 2008).

These studies examine different hypotheses and use different data sets, but they have one common feature: all find that a woman's educational attainment is an important correlate of when she marries. Specifically, all of these studies report that women with a university education are more likely to delay marriage. ${ }^{7}$ With regard to the question of whether this delay translates into a lower overall likelihood that university-educated women marry, the studies are not definitive. Results differ depending on the set of explanatory variables held constant in the analyses: for example, Raymo (2003) estimates a set of alternative models which yield contrasting results on this point.

\footnotetext{
${ }^{7}$ Even though university-educated women delay marriage while in school, they catch up to some extent later- the difference in mean age at marriage between university graduates and high school graduates is substantially less than four years (see Shirahase 2000, especially Table 1).
} 
Other factors that have been found to be statistically significant in one or more of these various studies are: the woman's age; measures that represent various aspects of the labor market for both men and women, including the woman's own income; measures that represent socioeconomic characteristics of her parents, including their income, health, and work status; measures that reflect income or other transfers from her parents, including housing; characteristics of the woman's natal family; demographic measures that reflect the availability of potential spouses; and the region in which she lives and its rural/urban characteristics.

\section{A Model of Joint Education and Marriage Decisions}

Pulling together the findings cited above, we see that the EEOA is likely to have positively affected the probability that women attend university; that university-educated women are more likely than other women to be employed in full-time positions and to delay marriage; and that a woman's decision to marry is empirically related to her level of education, her family background, labor market conditions at the time of her graduation and thereafter, and her earnings and income. The papers on marriage referenced above do not incorporate in their models the possibility that marriage and education are jointly determined; nor do they consider the possibility that the EEOA might be related to marriage decisions. The model described below incorporates these innovations.

\section{$\underline{\text { The Japanese Context }}$}

Japanese women typically choose between two types of post-high school educationuniversity and junior college — but it is university education that provides the background for a 
career. ${ }^{8}$ Junior college curricula are typically limited and three-quarters of them "offer a single curriculum in non-vocational subjects, such as music, home economics, and English literature" (Ishida 1998). Junior college education is likely to be better preparation for marriage than for career employment, and the financial returns from a junior college education may run predominantly through the marriage market as compared to the labor market. University education, in contrast, offers a curriculum that provides superior preparation for career employment, though it too may improve a young woman's marriage prospects. ${ }^{9}$ The education decision we focus on, therefore, is the decision to attend or not attend university.

A distinguishing feature of Japanese higher education is that, unlike the United States where people leave and re-enter post-high school educational institutions at various points in life, education in Japan is more structured; few women are in any type of formal schooling after marriage. In addition, the path to university education is well defined, so that without proper preparation in the high school years (or even before, in some cases), a Japanese student cannot expect to enter university. ${ }^{10}$ These features provide the setting within which education decisions are made in Japan.

\footnotetext{
${ }^{8}$ Other post-high school options are colleges of technology and specialized training colleges, which provide a wide variety of vocational and practical skills but are not typically considered to be comparable to university, though in some cases they may be comparable to junior colleges.

${ }^{9}$ In the context of the United States, Goldin (1992), Lengren and McIntyre (2006), Ge (2011) and others have shown that a large part of the returns to university education is via the marriage market: by attending university, young women come in contact with highly educated young men who will have greater future earning power. For example, doing a "back-of-the-envelope" computation, Lengren and McIntyre estimate that about half of the increase in a woman's "available income" (including income that she receives through her marriage) associated with her own higher education comes through the marriage market

${ }^{10}$ This characterization of access to university education is appropriate at the time the women in this sample were attending university, but more recently there have been changes. For example, in 1997 only 5\% of private universities fell below their enrollment limits, but by 2008 the situation had changed dramatically, with $47 \%$ of
} 


\section{The Model}

The model we sketch out below captures in stylized form this context and is similar in spirit to the model outlined by Lefgren and McIntyre (2006) (hereafter referred to as L\&M). L\&M posit a two-period model in which a woman's education decision is made in the first period and her marriage decision is made in the second period. ${ }^{11}$ They also postulate that a woman's education does not directly affect her "draw" in the marriage market, but because higher education is associated with higher earnings, her education does affect whether or not a particular draw from the distribution of potential husbands will be acceptable to her. The higher her own level of education, the fewer the number of men acceptable to her as a potential spouse. In this model, the resulting relationship between educational attainment and marriage can be positive or negative, depending on whether a woman's higher level of education has a stronger effect on her own earnings or on her share of her husband's earnings. ${ }^{12}$ L\&M also show, as we will below, that a woman's educational choice is related to her future marriage expectations and

private universities falling below their enrollment limits. As a result, more universities are now enrolling students with lower test scores than would have been acceptable in the past; such universities have been dubbed "free-pass" universities by the Japanese media. For a detailed discussion of recent changes in Japanese higher education see Igami (2014).

11 L\&M apply this two-period model to data for the United States, but the model is more appropriate in the context of Japan than it is for the United States, where it is not at all uncommon for people to enter and/or reenter university after marriage or after having had children.

${ }^{12}$ L\&M use an instrumental variable strategy to estimate their model using data from the 2000 U.S. Census of Population. They find that women's education "appears to have a substantial causal effect on husband's earnings" (p. 788) but has a relatively small impact on a woman's probability of marriage. Another paper that looks at the interrelationship between education and marriage decisions in the U. S., Ge (2011), focuses on the increased financial gains from marriage obtainable by attending college (because of the better set of potential spouses from which to choose). Ge reports that the expected financial gains from marriage are a significant determinant of a woman's decision to attend college, but has a much less impact on her college completion. 
that not taking into account this potential endogeneity can lead to biased coefficients of the education variable in a marriage equation.

While our model is inspired by L\&M, it differs because we focus on tracing the effects of the EEOA on the interrelated decisions regarding education and marriage rather than on measuring the economic status of women before and after marriage. We assume that a young woman's (and her family's) decision with regard to whether or not she will get a university education is well defined by the time she is near the end of high school-- at age 17 (this age corresponds to period one in L\&M's model). Variables that affect this decision would include family demographic and socioeconomic characteristic, the expected costs and returns to a university education, and unmeasured ability and taste factors that reflect a young woman's desire for career employment and marriage. The marriage decision is assume to take place after her education is completed (this corresponds to period 2 in the L\&M model), and is determined by the young woman's educational attainment (which, in line with L\&M, will affect her financial returns to marriage), her family background, various indicators of the states of the marriage and labor markets, and unmeasured taste and culture factors that influence both her career aspirations and her judgment about the desirability of marriage.

The features described above are best captured by a recursive bivariate probit statistical model, represented mathematically below (see Greene 2008, pp. 823-826 for a discussion of this model).

$$
\begin{gathered}
y^{*}=x_{e}^{\prime} \beta_{e}+\alpha_{e} E E O A+\varepsilon_{e}, \quad y=1 \text { if } y^{*}>0,0 \text { otherwise, } \\
z^{*}=x_{m}^{\prime} \beta_{m}+\alpha_{m} E E O A+\gamma y+\theta(y \times E E O A)+\varepsilon_{m}, \quad z=1 \text { if } z^{*}>0,0 \text { otherwise, } \\
\left(\begin{array}{c}
\varepsilon_{e} \\
\varepsilon_{m}
\end{array}\right) \sim N\left(\left[\begin{array}{l}
0 \\
0
\end{array}\right], \quad\left[\begin{array}{ll}
1 & \rho \\
\rho & 1
\end{array}\right]\right)
\end{gathered}
$$


In this system of equations, the dichotomous variable $y$ represents whether or not a young woman completed university, ${ }^{13} \mathrm{z}$ represents whether or not she has been married by the age of $32^{14}$, and $y^{*}$ and $z^{*}$ denote latent variables of $y$ and $z$, respectively. The factors which affect the education decision, denoted by $x_{e}$, are similar to those in Edwards and Pasquale (2003), while the error term $\varepsilon_{e}$ picks up unmeasured ability, tastes for education, taste for marriage, and taste for career employment, all as of the time the young woman is making her higher education decision. The factors that affect the marriage decision, denoted by $x_{m}$, follow closely the marriage literature cited earlier, while the random error term, $\varepsilon_{m}$, picks up various luck factors that determine a marriage match and also the young woman's unobservable taste for career employment and marriage at the time of completing her education. The variables in $x_{e}$ and $x_{m}$, which have some common elements, are described in detail in the next section. The dichotomous variable EEOA, appearing in both equations, indicates whether or not a young woman's education decision was made before or after the passage of the EEO Act.

There are two other things to note about the econometric model. First, the error terms in the education and marriage equations may be correlated because they both include components that represent unmeasured tastes for marriage and career employment. Such a correlation implies that educational attainment is an endogenous variable in the marriage equation $\left(\operatorname{Cov}\left[y, \varepsilon_{m}\right] \neq 0\right)$.

\footnotetext{
${ }^{13}$ Like L\&M, we posit these relations in the form of regression equations. In an appendix, L\&M sketch out how regression equations such as these could be derived, with a set of appropriate simplifying assumptions, from a utility maximization framework. Note also that the first equation in the system is similar to the estimating equation in Edwards and Pasquale (2003), which is derived from a random utility model.

${ }^{14}$ In this paper, since we are focusing on the marriage decision, we define our marriage variable to include anyone who at the point when we observe her had decided to become married, whether or not that marriage ended in divorce. Note that divorce is relatively rare in Japan, at about 2 per 1000 population in 2010 (Japan Ministry of Health, Labour and Welfare 2015). In the JPSC data, approximately $1.0 \%$ of the previously married women get divorced every year.
} 
Indeed, including the education variable, which is the dependent variable in the first equation, in the marriage equation as an explanatory variable is what distinguishes this statistical model from a non-recursive model. ${ }^{15}$ Second, we include an interaction term between the education variable and the EEOA variable, as explained below, in order to see if the effect of education on marriage changes after the passage of the EEO Act.

\section{Data and Variables}

The data used to estimate our model come from a unique micro-level panel survey entitled the Japanese Panel Survey of Consumers (JPSC), a nationwide longitudinal survey of young Japanese women and their husbands sponsored by the Institute for Research on Household Economics (Kakei Keizai Kenkyujo) in Japan. These data are especially suitable for our study because they provide a rich set of information about women's family background, education, and marriage. The first wave (Wave A) of this survey was conducted in 1993 and included 1500 randomly selected women aged 24-34 in that year. ${ }^{16}$ Subsequent waves (B and C) were added to the sample in 1997 and 2003: Wave B included 500 women aged between 24 and 27 years in 1997; and Wave C included 836 women aged between 24 and 29 years in 2003. As of 2008, there remained approximately 1,650 respondents aged between 29 and 49 in the JPSC.

The structure of the data set is illustrated in Figure 2. Each row in the figure corresponds to a year and shows the number of women of each age for whom data are reported for that year.

\footnotetext{
${ }^{15}$ Green (2008) notes, however, that in models such as this one, the endogenous nature of education variable in marriage equation "can be ignored in formulating the log-likelihood" (page 823). Hence, in the estimation we are able treat the education variable in marriage equation as if it were exogenous.

${ }^{16}$ The survey originally contacted 3,623 randomly selected women in this age group, of whom 1500 were ultimately selected to be in the first wave of the panel. Demographic characteristics of these participants were comparable to those of the same age group in the Population Census (Higuchi 2001).
} 
For example, in 1993, the first survey year of Wave A, there were 151 women aged 24, 161 aged 25, and so on, for a total of 1500 women aged 24 to 34 in that year. In the following year, 1994, the women have aged one year and there is some attrition, so that there are no women aged 24, 145 aged 25 ( 6 women from that age-cohort had dropped out of the survey over the year), 146 aged 26, and so on, for a total of 1415 women aged 25 to 35 in that year (total attrition was 85). Things continue in a similar fashion in 1995 and 1996. Wave B begins in 1997, with a new group of 24 to 27 year-old women added to the survey, and Wave $\mathrm{C}$ begins in 2003, with an additional group of women aged 24 to 29 added in that year. From this diagram we can compute that the potential number of women for whom we would have family background and education information-- both of which come from the questionnaire administered in the initial survey year for each wave-- is 2836. Because of missing observations for some of these variables, our actual sample consists of 2598 women.

Looking at Figure 2 in a slightly different way, one can see that each column shows the number of observations available for women of a specified age but at different points in calendar time. For example, if one wanted to study women at age 32, there would be 122 of them observed in 1993, 124 observed in 1994, and so on, for a total of 1641 women in the sample who responded to the survey at age 32. Also indicated in this figure is whether women of a particular age in a particular year are members of the pre-EEOA cohort or the post-EEOA cohort. The preEEOA cohort is defined to be women aged 18 or older in 1985, the year that the EEO Act was passed; women in this cohort appear in the figure above the dotted diagonal. The post-EEOA cohort of women is defined to be those who were aged 17 or younger in 1985; women in this cohort appear below the dotted diagonal. 
Our choice of marriage variable — whether a woman is or has been married by age 32 requires some explanation. Ideally, we would observe marital status at an older age because not all women who plan to marry will in fact be married by age $32 .{ }^{17}$ However, given the construction of the sample and sample attrition, the later the age at which we observe marital status, the fewer observations will be available. Further, if we choose to observe marital status at a later age, the balance between the pre-EEOA and post-EEOA samples is reduced. Thus, our choice is a pragmatic one: by observing women at age 32 , we will capture a large proportion of marriages while still having a large enough sample size to address our main hypotheses. ${ }^{18}$

Among our working sample of 2598, there are 2157 women for whom marital status at age 32 can be determined. The difference between these two numbers is attributable primarily to: (1) women who remained in the survey through 2008 but had not yet reached age 32 and had not yet married; and (2) women who had dropped out of the sample before age 32 and had not married prior to dropping out.

The variables used in our estimation are defined in Table 1, along with the data sources for variables that are not taken from the JPSC. The variables that do not come from the JPSC are measured at the level of the prefecture in which the young woman resided as of age 17. The final two columns of the table indicate whether the variable appears in the education equation, the marriage equation, or both.

\footnotetext{
${ }^{17}$ Because of the lock-step nature of higher education in Japan, we can be confident that women who had chosen university education will have completed it by age 32 . Indeed, only 28 people in the entire JPSC sample are enrolled in any kind of schooling after the age of 32.

${ }^{18}$ The mean age at first marriage for women in Japan over the time period covered in our data ranged from 25.9 (in 1990) to 28.8 (in 2010) (Japan Ministry of Health, Labour and Welfare 2015).
} 
The variables in $x_{e}$ are similar to those in Edwards and Pasquale (2003) and include: characteristics of the woman's family background (parents' educational attainment, family income, whether the young woman attended private high school, her number of siblings, whether she has any brothers, and whether her mother was primarily a homemaker); proxy measures of her academic ability (attendance at juku ("cram school”) in elementary (Juku 2), junior high (Juku 3), and high school (Juku 4)); proxy measures for the availability and opportunity costs of university education in her area as measured at her age 17 (the ratio of professors to high school graduates and the vacancy/application ratio); a proxy for the expected returns to university education (the ratio for males of the starting wage for university graduates relative to that of high school graduates) ${ }^{19}$; and a dummy variable indicating whether the EEOA was in effect when she was 17 years old, which is the age at which we assume her final decision with regard to university education is made. As discussed earlier, the latter variable is included because the EEOA aimed to increase women's access to career employment (and the resulting higher lifetime earnings), and university education is the traditional route to this type of employment.

In the case of the marriage equation, the explanatory variables $x_{m}$ represent factors suggested by the economic and demographic literature surveyed in the previous section. Educational attainment has been found to be an important variable in marriage decisions in almost all of the literature that we surveyed and falls directly out of the L\&M utility maximization model described above; our education dummy variable indicates whether or not the young woman completed university. Family background variables like parents' income,

\footnotetext{
${ }^{19}$ This variable is not specific to the prefecture, but is rather a national average.
} 
family structure (number of siblings and whether there is a male sibling), and whether the woman's mother was a full-time homemaker are also commonly used. To represent the state of the labor market around the time that the young woman completes her education a variety of proxies have been used (see Higuchi (2001), Hashimoto and Kondo (2010), and Sakamoto and Kitamura (2008)). We use the prefecture vacancy/application ratio at the age she completes her schooling to proxy the strength of the labor market she faces post-schooling. ${ }^{20} \mathrm{~A}$ higher vacancy/application ratio indicates a stronger job market, which may be positively or negatively related to the probability of marriage. ${ }^{21}$ In addition, following Abe (2013), we include two city size variables to proxy the state of the labor market for university-educated women.

To capture the state of the marriage market we use several variables. The availability of potential spouses with a level of education equal to that of the woman's (found to be an important factor by Raymo and Iwasawa 2005) is computed for each birth cohort for each prefecture as follows: for women who did not have a university degree, we use the ratio of the number of (two years older) male high school graduates (with or without a university education) to female high school graduates (without a university education); for women who had a university degree, we use the ratio of the number of (two years older) male university graduates to female university graduates. ${ }^{22}$ We expect this variable to be positively related to the woman's probability of marriage. The cost of setting up a household is proxied by rent per tatami mat (in

\footnotetext{
${ }^{20}$ The age at which a woman's education is completed is assumed to be 18 for a high school graduate, 21 for a junior college or vocational school graduate, and 23 for a university graduate.

${ }^{21}$ Miyoshi (2014) and others, noting that a strong labor market affects both a woman's expected earning power and the earning power of a potential spouse, refers to the positive relationship the "self-reliance effect" and the negative relationship the "good catch effect".

${ }^{22}$ It is difficult to find data that would have allowed us to compute a more refined measure of spouse availability at the prefecture level within Japan.
} 
constant yen) in the woman's prefecture as of the year she completes her education. The search costs associated with finding a mate and also varying cultural norms regarding marriage are proxied by the two city size variables mentioned above (Sakai 2009).

To explore the potential impact of the EEOA, we include in the marriage equation the EEOA dummy variable as defined above as well as an EEOA/education interaction term. This interaction term, which enables us to estimate separate education coefficients for pre- and postEEOA cohorts, permits us to test the hypothesis that the passage of the EEOA increased the "deterrent" effect of university education on marriage.

In addition to these variables we include in both the education and marriage equations a set of dummy variables that indicate the geographic district in which the woman lived when she was aged 17 (Japan is divided into ten such districts). ${ }^{23}$ These are included to hold constant any district-specific unmeasured taste, economic, or cultural factors that may affect education or marriage decisions. Finally, in some specifications, we include a linear time trend variable. Descriptive statistics for all variables are shown in Table 2.

\section{Results}

Table 3 presents maximum likelihood estimates of our model. In discussing these estimates, we concentrate on the sign and significance of the coefficients and on comparing the two specifications. We do not discuss the magnitude of the probit coefficients because they are

\footnotetext{
${ }^{23}$ It is possible that women will not be living in the same district at the time they make their marriage decision as when they were age 17, but the JPSC data do not permit us to identify the district in which each woman lives subsequent to age 17. The ten districts (called Chiho in Japanese) are Hokkaido, Tohoku, Minami-Kanto, KitaKanto\&Koshin, Hokuriku, Tokai, Kinki, Chugoku, Shikoku and Kyushu.
} 
not readily interpretable. To evaluate magnitudes requires the estimation of partial effects, which appear in Table 4.

We begin with the estimates in column $1 .{ }^{24}$ Looking first at the education equation, we see that, overall, the variables do a good job of explaining young women's decisions with regard to university education: most of the coefficients are statistically significant and have signs consistent with our expectations and with the findings of Edwards and Pasquale (2003). ${ }^{25}$ Family background variables such as family income, parents' education, and number of siblings are significant predictors of the probability that a young woman will attend university, with a positive association between parents' income and education and a negative association between family size and education. Having a brother has a negative sign, but is not statistically significant. However, having a mother who was a full time homemaker is positively and significantly related to a young woman's likelihood of attending university; perhaps having one's mother available full time facilitates the young woman's study. Surprisingly, attending a private high school, which is included as a supplementary wealth measure and also may represent the parents' taste for education, has a negative and significant relationship with the young woman's probability of attending university. With regard to academic ability, attending juku in elementary and/or junior high school are indicators of a lower than average level of ability, and attending juku in high school is an indicator that the young woman has a high enough level of ability to

\footnotetext{
${ }^{24}$ The education equation is estimated using our entire sample of 2598 observations, while the marriage equation uses the 2157 observations for which marriage data are reported. That is, the observations without marriage information contribute to the likelihood function of education only. The main difference between these two samples is that the smaller sample is slightly older and (consequently) has a slightly lower proportion of university graduates. Put differently, those who do not report marital status are more likely to be from recent cohorts and more likely to be university graduates.

${ }^{25}$ Note that Edwards and Pasquale (2003) is not perfectly comparable with this paper because it employs three education categories (university, junior college, and all other education) and a logit econometric model.
} 
contemplate university. ${ }^{26}$ The coefficients of all three juku variables have signs in the expected direction--negative in the case of Juku 2 and Juku 3 and positive in the case of Juku 4, --and the latter two are statistically significant.

The variables included to capture the returns to and costs and availability of university education do not have statistically significant coefficients. The vacancy/application ratio observed when the woman is aged 17 , used to proxy the opportunity cost of attending university, has a negative sign as expected but not statistically significant; the negative sign means that the higher this ratio-- corresponding to a more favorable labor market-- the less likely is a young woman to attend university. The variable included to proxy the "supply" of university places in the young woman's prefecture, the professor/high school graduate ratio, which we expected to have a positive sign, has a negative sign but it is not statistically significant. The variable included to proxy the expected returns to a university education-- the ratio of the starting wage for male university graduates to the starting wage for male high school graduates-- has a positive coefficient, as expected, but is not statistically significant. It may be that these variables do not well represent the underlying costs and returns factors we are trying to measure.

Finally, the EEOA variable has a positive and statistically significant coefficient, implying that young women who were making their higher education decisions after the EEOA had been passed were more likely than comparable women from earlier cohorts to attend university.

Estimates of the marriage equation appear below those of the education equation. Consider first the role of having a university education. Consistent with the studies of marriage

\footnotetext{
${ }^{26}$ See Edwards and Pasquale (2003) for a more detailed discussion of using attendance at juku as a proxy for ability.
} 
cited earlier, we find that women's university education has a negative association with marital status by age 32 . However for pre-EEOA cohorts this relationship is not statistically significant. Conversely, the coefficient of the Education/EEOA interaction term is negative and significant, yielding the result that for post-EEOA cohorts there is a statistically significant negative effect of university education on marriage. To be more specific, the probit coefficient for pre-EEOA cohorts is -.324 and not statistically significant, while for post-EEOA cohorts it is more than twice as large, at $-.680(-.324+(-.356))$, and statistically significant. This result is consistent with the hypothesis that the "deterrent effect" of university education on marriage increases significantly after the passage of the EEOA. Interestingly, the EEOA dummy variable itself is not statistically significant, indicating that the EEO Act had no added effect on marriage beyond that which operates through university education.

The role of the family background variables is mixed. Higher family income is associated with a lower probability of marriage, as is having a mother who is a full-time homemaker, but these are not statistically significant relationships. In contrast, having more siblings has a significant positive relationship to the probability of marriage, while having at least one brother has a significant negative relationship with the probability of marriage. Having more siblings may reduce a young woman's responsibilities with regard to caring for aged parents, thereby making it more feasible for her to marry. It is unclear why having a brother would be negatively associated with the likelihood of marriage.

Other variables in the marriage equation are proxies for aspects of the marriage market and/or the labor market. The two city size variables-large city and medium city-- reflect unmeasured aspects of both the labor market and the marriage market. The signs of both variables are negative and significant, with the coefficient of large city greater in absolute value 
than the coefficient of medium city. This result implies that the larger the city in which a woman lives the less likely she is to have married by age 32, a result consistent with the findings in Sakai (2009). Rental costs are also significantly related to the likelihood of marriage and in the expected direction, with higher rental costs associated with a lower probability of marriage. The other measure that proxies the state of the marriage market, spouse availability, is not statistically significant and its sign is the opposite what we expected: the greater the availability of potential spouses, the lower the probability of women's marriage. The vacancy/application ratio, included to capture the state of the labor market, has a negative, statistically significant sign, consistent with the findings of Higuchi (2001) that women are less likely to marry when the job market is strong.

Two other findings in Table 3 should be pointed out. First, the estimated value for the coefficient of correlation between the error terms in the education and marriage equations is positive but small (.033) and not statistically significant. This means that the potential correlation between unmeasured characteristics of the young woman that affect both education and marriage is not large enough to affect our estimates. Second, more than half of the district dummy variables are statistically significant, indicating that it is important to include these variables to hold constant cross-sectional social and economic differences that are not fully captured by the socioeconomic variables included in the analysis.

We next explore a variation in our model. One could argue that the results in column 1 with regard to the relationships among the marriage, education, and EEOA variables are simply reflecting secular trends in cultural attitudes towards the role of women in society rather than any "cause and effect" relationship among these three variables. Put differently, it could be argued that the EEOA variable in both equations and the education and education/EEOA variables in the 
marriage equations are simply proxies for this secular change in attitudes rather being in of themselves factors in women's decision making. If this argument were true, a trend variable added to our estimating equations would be statistically significant and knock out some or all of the other variables that have monotonic trends.

We carry out this robustness test by adding a trend variable to the specifications in column 1 of Table 3 . This variable ("Trend") is coded at one for the oldest cohort in our data (those born in 1959) up to 21 for the youngest cohort (born in 1979). The resulting estimates appear in column 2. As might be expected, the coefficient of Trend has a positive sign in the education equation and a negative sign in the marriage equation. However, in both cases the coefficients are not statistically significantly different from zero. Thus, adding this variable does not contribute significant explanatory power to our economic model. What including this variable does do, however, is to sap some strength from the EEOA variable. Specifically, the coefficient of the EEOA variable in the education equation drops to virtually zero and loses statistical significance. Notably, what is not affected by the addition of Trend is the coefficient of the education/EEOA interaction in the marriage equation; this interaction maintains its statistically significant negative sign (though its coefficient shrinks slightly in absolute value).

\section{Further Results: Partial Effects}

We have now identified the statistically significant variables that influence the university education and marriage decisions of young women, but it is well known that statistical significance does not necessarily translate into practical economic or social impact. To see which variables are of consequence to decision making, we compute partial effects. These partial effects are shown in Table 4 and are computed as follows. In the case of binary 
explanatory variables, the partial effect is the change in the value of the dependent variable associated with shifting the value of the binary variable from zero to one while holding constant all other explanatory variables. In the case of non-binary discrete variables, the partial effect is the change in the value of the dependent variable associated with a one unit increase in the explanatory variable, again holding constant all other explanatory variables. For both types of discrete explanatory variables, we compute the partial effects using the finite-difference method. For continuous explanatory variables, we compute the partial effects using calculus method. In all cases, we compute the partial effects for each observation and then compute of the averages of these effects to yield average partial effects (see Greene (2008) or Hasebe (2013) for details of partial effects in the recursive bivariate probit model). Standard errors are computed using the bootstrap method with 100 replicates.

There is an added wrinkle to computing partial effects in a recursive model: variables that affect the education decision also affect the marriage decision, but indirectly, via education's impact on marriage. Therefore, for the marriage equation three types of partial effects are shown: direct partial effects (col. 1) - those that pertain to the explanatory variables $\left(x_{m}\right)$ that appear in the marriage equation--; indirect partial effects (col. 2)-those that pertain to explanatory variables $\left(x_{e}\right)$ in the education equation--; and total partial effects (col. 3) - the sum of direct and indirect partial effects. In the case of the education equation, there are no indirect partial effects, so the direct and total partial effects are the same.

The partial effects reported in Table 4 correspond to the two specifications in Table 3: Panel A contains partial effects computed from the coefficient estimates in column 1 (trend variable excluded), while Panel B contains those computed from those in column 2 (trend variable included). In our discussion of this table we focus on the partial effects that are 
statistically significant, but for the interest of the reader, we have included partial effects for all variables. Recall that partial effects are computed for each variable holding constant all other variables and are therefore not additive.

To get a sense of the scale of these partial effects, it is useful to keep in mind the level and changes in the prevalence of university education and marriage across the cohorts in our sample. The percent of women in our sample with a university education ranged from $11 \%$ in the earliest cohort to $25 \%$ in the final cohort, an increase of 14 percentage points. Over the same period, the percent of 32 year-olds ever married ranged from $100 \%$ in our earliest cohort to $73 \%$ in the final cohort, a decline of 27 percentage points.

The first thing to point out about Table 4 is that for many of the variables, the partial effects are virtually the same in both Panels A and B. Much of our discussion, therefore, does not distinguish between the results in the two panels. Only when there are differences do we discuss the results in Panels A and B separately.

Consider first the education equation. It is evident in Table 4 (both panels) that family background variables play the strongest role in decisions regarding university education. The partial effect of mother's education is by far the largest: having a mother with a university education is associated with an increased probability that a young woman herself completes university by 24 percentage points. Having a father with a university education is almost as powerful, associated with a 18 percentage point increased likelihood of completing university, as is attending juku in high school, which is associated with a 19 percentage point increase in the likelihood of completing university. Being in a high income category is also associated with a large partial effect, as compared to being in the lowest income category, at 10 percentage points. 
Other family background variables that are statistically significant have lesser partial effects, ranging from 2 to 4 percentage points.

There are two variables in the education equation for which the results in Panels A and B differ. The first is the vacancy/application rate, which has a statistically significant partial effect of -.031 in Panel A and a non-significant partial effect of -.028 in Panel B. This difference, however, if of little practical import: a one-standard-deviation increase in the vacancy/application rate is associated with a decline of 1.4 percentage points in the first case and 1.2 percentage points in the second case.

The other significant variable for which there is a difference between the two panels is EEOA. In Panel A, being a member of the post-EEOA cohort is associated with a 3 percentage point higher likelihood that a young woman will complete university, as compared to members of the pre-EEOA cohort, whereas in Panel B this partial effect loses significance and is reduced to virtually zero. Thus, with this range of partial effect estimates for the EEOA variable -0 to 3 percentage points - we cannot draw an unambiguous conclusion about the importance of the EEO Act on young women's decisions regarding university education.

Moving to the marriage equation, consider first the direct partial effects. The single most important variable, in terms of the magnitude of the partial effect, is education. For pre-EEOA cohorts a university education is associated with a 7 to 8 percentage point reduction in the likelihood that a young woman has married by age 32, though this partial effect is not statistically different from zero. For post-EEOA cohorts, however, the partial effect is much larger and statistically significant - ranging from -16 to -19 percentage points. Given the fact that in our sample the proportion of 32-year-olds who have married falls by 27 percentage points 
over the period in our study, the magnitude of this latter partial effect is remarkable. This result clearly supports the proposition that university-educated women believe that they can best take advantage of the enhanced career options associated with the passage of the EEO Act by delaying or declining marriage.

Among the other statistically significant direct partial effects, city size is important: women from large cities are 5 percentage points less likely to be married as compared to small cities, and the corresponding difference is 4 percentage points for middle-sized cities versus small cities. The number and gender of siblings also has a similar impact: having an additional sibling is associated with about a 4 percentage point increase in the probability of marriage, while having at least one brother is associated with a 3 percentage point decline. The partial effects of the rent and labor market variables are comparable in magnitude to those of these two family structure variables: a one standard deviation increase in monthly rent (which corresponds approximately to a one thousand yen increase) is associated with about a 4 percentage point decline in the likelihood of marriage, and a one standard deviation increase in the vacancy/application ratio is associated with a decline of 3 percentage points. In contrast to the case of the education decision, for the marriage decision the partial effect of the EEOA dummy in both Panels A and B is never significantly different from zero.

Beyond these direct effects, a number of variables have significant indirect effects on marriage through their effects on education, with their sign in marriage equation opposite to their sign in the education equation. These tend to be of a smaller magnitude than the direct partial effects and with one exception, are statistically significant only in Panel A, The exception is the mother's education variable: women whose mothers were themselves university graduates have a 3.2 to 3.7 percentage point lower probability of marriage by 32 , as compared to other 
women. In the case of the six variables where both direct and indirect partial effects on marriage are pertinent — middle income, high income, homemaker, sibling, brother, and EEOA--, the contribution of the direct partial effect dominates the contribution of the indirect partial effect so that the conclusions we drew when we discussed the direct effects remains unchanged.

What conclusions can we draw from these results? First, young women's decisions with regard to university education are determined primarily by her parents' education and income, by the young woman's ability, and by her family's structure. Economic factors that reflect the costs and returns to education do not play a significant role in this analysis. The role of the EEOA is unclear: with a range of estimates of partial effects of 0 to -3 percentage points, our results are suggestive but inconclusive.

Second, it is clear that young women's decisions with regard to university education and marriage are closely interlinked. The single most important variable from among those we study in determining whether a woman is married by age 32 is whether or not she has a university education, but notably, this strong linkage is found only for post-EEOA cohorts. For pre-EEOA cohorts, university-educated women are estimated to be 7 to 8 percentage points less likely to married by age 32 , compared to their less-educated contemporaries, but this estimate has such a large variance that it is not statistically significant. In contrast, for post-EEOA cohorts, we see a strikingly large, statistically significant partial effect of university education on marriage by age 32 , in the range of 16 to 19 percentage points. There is also an intergenerational aspect to the role of education in marriage which operates indirectly, with women whose mothers or fathers had a university education approximately 3 percentage points less likely to be married by age 32 . 
Third, other factors affect marriage decisions by age 32, but to a lesser extent. Marriage is less likely for women who live in large or middle-sized cities or who have a male sibling. In contrast, having additional siblings (holding their sex constant) is associated with a higher likelihood of marriage. The role of the labor market is similar to that reported by other researchers: when the vacancy/application rate is higher, and jobs more plentiful, women are less likely to be married by age 32. Also, when the cost of setting up a marital home, as reflected by average rental costs, is higher, women are less likely to be married by that age. The passage of the EEOA does not appear to have had an important impact in of itself, but rather operates by increasing the responsiveness of the marriage decision to university education, as described above.

\section{Conclusions}

Prompted by declines in Japanese birth rates and marriage rates over the past thirty years, this paper seeks to understand how women's declining propensity to marry interacts with the growth over the same period in women's propensity to attend university, and how both of these latter two trends may have been impacted by the passage in 1985 of the Japanese Equal Employment Opportunity Act (EEOA). Using data from a unique Japanese panel survey, the Japanese Panel Survey on Consumers (JPSC), we estimate a model that treats education and marriage decisions as jointly, though not simultaneously, determined. Specifically, we use a recursive bivariate probit econometric model to capture the particular context within which education and marriage decisions are made in Japan.

Our empirical results provide support for the second and third hypotheses we set out earlier, but not for the first. In the case of our first hypothesis, our evidence about the role of the 
EEOA in university-education decisions does not provide unambiguous support. In the case of the second and third hypotheses, we find that women who were university educated had a lower probability of being married by the age of thirty-two, as compared to other similar women, and that the deterrent effect of university education is significantly greater for post-EEOA cohorts than for their predecessors. Overall, our research strongly suggests that the Japanese Equal Employment Opportunity Act and the expansion in career opportunities it made available to university-educated women was a contributory factor in the decline over the past 30 years of marriage in Japan. 


\section{References}

Abe, Yukiko, 2010. Equal Employment Opportunity Law and the gender wage gap in Japan: a cohort analysis. Journal of Asian Economics, 21:2, 142-155.

Abe, Yukiko, 2011. The Equal Employment Opportunity Law and labor force behavior of women in Japan. Journal of the Japanese and International Economies, 25:1, 39-55.

Abe, Yukiko, 2013. Long-Term Impacts of the Equal Employment Opportunity Act in Japan. Japan Labor Review, 10:2, 20-34

Araki, Takashi, 1998. Recent legislative developments in equal employment and harmonization of work and family life in Japan. Japan Labour Bulletin, 37 (4) at www.jil.go.jp/jil/bulletin/year/1998/vol37-04/05.htm, accessed November 11, 2010

Becker, Gary S. 1976. The Economic Approach to Human Behavior. Chicago, IL: University of Chicago Press.

Becker, Gary S. 1993. Human Capital, $3^{\text {rd }}$ Ed. Chicago, IL: University of Chicago Press.

Brien, Michael J. and Michelle Sheran, 2003. The Economics of marriage and household formation. In: Grossbard-Schechtman, Shoshana (Ed.). Marriage and the Economy. Cambridge, U.K.: Cambridge University Press, 37-54.

Edwards, Linda N., 1994. The Status of women in Japan: Has the Equal Employment Opportunity Law made a difference? Journal of Asian Economics 5:2, 217-240. 
Edwards, Linda N. and Margaret K. Pasquale, 2003. Women's higher education in Japan: Family background, economic factors, and the Equal Employment Opportunity Law. Journal of the Japanese and International Economies. 17, 1-32.

Ermisch, J., 2003. An Economic Analysis of the Family. Princeton NJ: Princeton University Press.

Faruqee, Hamid and Martin Mühleisen, 2001. Population aging in Japan: demographic shock and fiscal sustainability. International Monetary Fund Working Paper WP/01/40.

Ge, Suqin, 2011. Women's college decisions: How much does marriage matter? Journal of Labor Economics, 29, 773-818.

Goldin, Claudia, 1992. The meaning of college in the lives of American women: The past one-hundred years. Working paper no. 4099, National Bureau of Economic Research, Cambridge, MA.

Greene, William H., 2008. Econometric Analysis. Sixth edition. New Jersey: Prentice Hall.

Hasebe, Takuya, 2013. Marginal effects of a bivariate binary choice model. Economics Letters, 121, 298-301.

Hashimoto, Yuki and Ayako Kondo, 2012. Long-term effects of labor market conditions on family formation of Japanese youth. Journal of the Japanese and International Economies, 26(1), 1-22.

Higuchi, Yoshio, 2001. Women's employment in Japan and the timing of marriage and childbirth. Japanese Economic Review 52, 156-184. 
Ikezoe, Hirokuni, 2014. Work-life balance in Japan: Outline of policies, legal systems and actual situations. Japan Labor Review 11, 108-124.

Ishida, Hiroshi, 1998. Educational credentials and entry labor market outcomes in Japan. In: Shavit, Y., Muller,W (Eds), From School to Work: A Comparative Study of Educational Qualifications and Occupational Destinations. N.Y: Oxford University Press.

Japan Ministry of Health, Labour and Welfare, 2009, White Paper on Japanese Working Women. On line at http://www.mhlw.go.jp/bunya/koyoukintou/josei-jitsujo/09.html (accessed November 23, 2010)

Japan Ministry of Health, Labour and Welfare, 2010, Introduction to the revised Child Care and Family Care Leave Law. On line at http://www.mhlw.go.jp/english/policy/affairs/dl/05.pdf (accessed November 5, 2010)

Japan Ministry of Health, Labour and Welfare, 2015, Vital Statistics 2015.

Lefgren, Lars and Frank McIntyre, 2006. The relationship between women's education and marriage outcomes. Journal of Labor Economics 24, 787-830.

Miyoshi, Koyo, 2014. The labor market and marriage decisions in Japan. Japan Labor Review 11, 52-66.

Narayan, Paresh K. and Xiujian Peng, 2007. Japan's fertility transition: Empirical evidence from the bounds testing approach to cointegration. Japan and the World Economy 19, 263-278. 
Raymo, James M., 2003. Educational attainment and the transition to first marriage among Japanese women. Demography 40, 83-103.

Raymo, James M. and Miho Iwasawa, 2005. Marriage market mismatches in Japan: an alterntive view of the relationship between womens education and marriage. American Sociological Review 70, 801-822.

Sakai, Tadashi, 2009. Role of income to marriage behavior for Japanese women: marriage timing, desire to marry, actions toward marriage. The Japanese Journal of Social Security Policy 8, 20-32.

Sakai, Tadashi and Yoshio Higuchi, 2005. The long-term effect of the past unstable employment status (future outcomes of freeters). The Japanese Journal of Labour Studies 535, 29-41 (in Japanese).

Sakamoto, Kazuyasu and Yukinobu Kitamura, 2008. Marriage behavior from the perspective of intergenerational relationships. The Japanese Economy 34, 76-122.

Shirahase, Sawako, 2000. Women's increased higher education and the declining fertility rate in Japan. Review of Population and Social Policy 9, 47-63.

Tanaka, Yuko, 2014. The Family in Human Resource Management. Japan Labor Review 11, 67-85. 
Figure 1. Four-year University Advancement Rate, Unmarried Rate and Fertility Rate

$\%$

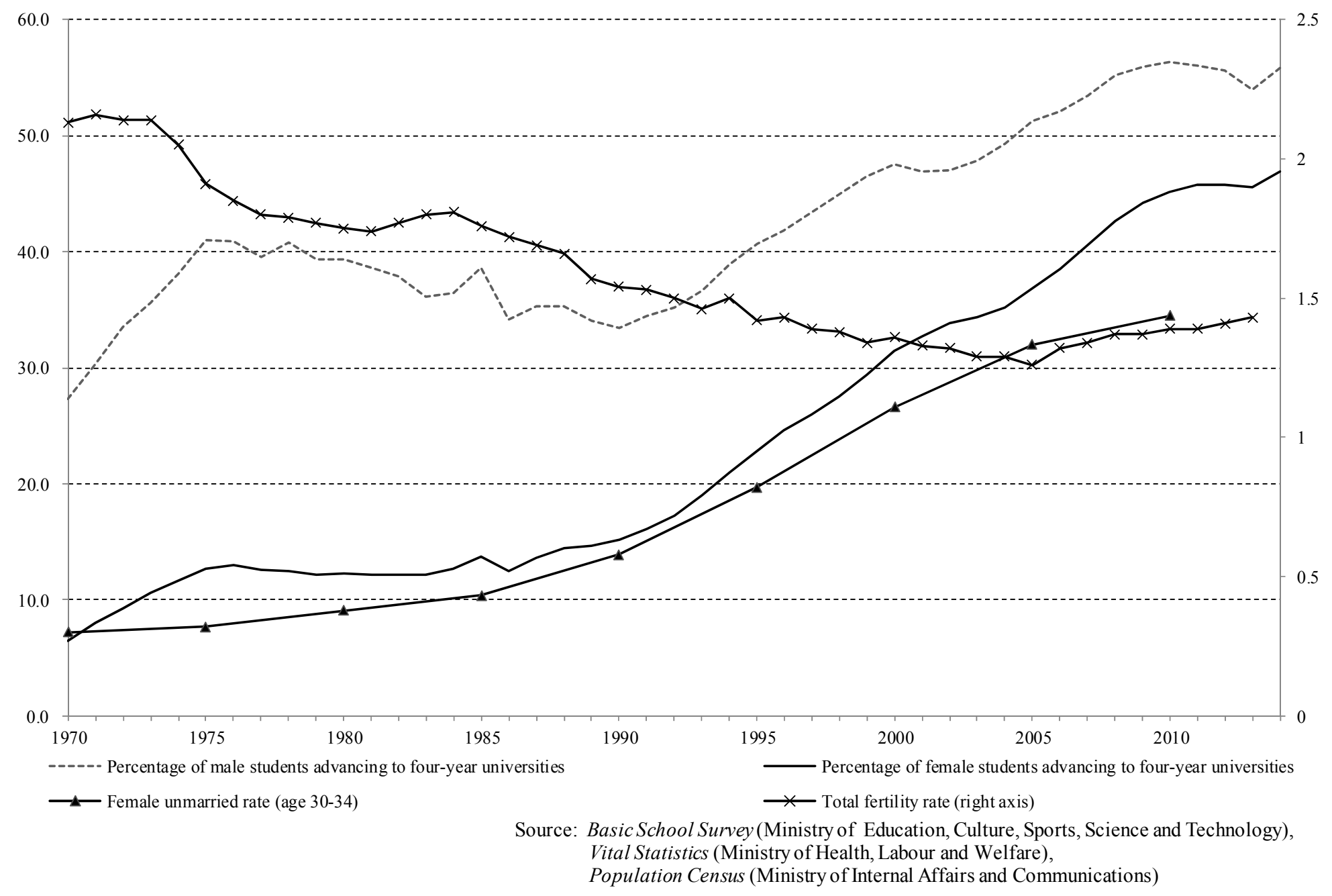


Figure 2. The Number of the JPSC Respondents by Age in each Year

\begin{tabular}{|c|c|c|c|c|c|c|c|c|c|c|c|c|c|c|c|c|c|c|c|c|c|c|c|c|c|c|c|}
\hline \multirow[b]{2}{*}{ Year } & \multicolumn{26}{|c|}{ Age } & \multirow{2}{*}{ Total } \\
\hline & 24 & 25 & 26 & 27 & 28 & 29 & 30 & 31 & 32 & 33 & 34 & 35 & 36 & 37 & 38 & 39 & 40 & 41 & 42 & 43 & 44 & 45 & 46 & 47 & 48 & 49 & \\
\hline 1993 & 151 & 161 & 145 & 115 & 144 & 125 & 143 & 132 & 122 & 106 & 156 & & & & & & & & & & & & & & & & 1,500 \\
\hline 1994 & & 145 & 146 & 136 & 108 & 136 & 115 & 138 & 124 & 117 & 101 & 149 & & & & & & & & & & & & & & & 1,415 \\
\hline 1995 & & & 134 & 139 & 127 & 100 & 133 & 109 & 130 & 119 & 109 & 96 & 145 & & & & & & & & & & & & & & 1,341 \\
\hline 1996 & & & & 132 & 128 & 122 & 98 & 126 & 107 & 128 & 107 & 105 & 93 & 143 & & & & & & & & & & & & & 1,289 \\
\hline 1997 & 125 & 131 & 127 & 117 & 126 & 121 & 121 & 96 & 121 & 103 & 128 & 103 & 103 & 92 & 135 & & & & & & & & & & & & 1,749 \\
\hline 1998 & & 110 & 121 & 107 & 97 & 118 & 121 & 114 & 91 & 112 & 95 & 122 & 98 & 97 & 91 & 134 & & & & & & & & & & & 1,628 \\
\hline 1999 & & & 104 & 110 & 104 & 88 & 107 & 114 & 107 & 88 & 109 & 88 & 117 & 95 & 93 & 88 & 125 & & & & & & & & & & 1,537 \\
\hline 2000 & & & & 99 & 103 & 99 & 82 & 108 & 109 & 105 & 85 & 106 & 88 & 112 & 91 & 91 & 84 & 119 & & & & & & & & & 1,481 \\
\hline 2001 & & & & & 94 & 97 & 93 & 80 & 105 & 106 & 102 & 82 & 97 & 84 & 108 & 89 & 86 & 83 & 115 & & & & & & & & 1,421 \\
\hline 2002 & & & & & & 88 & 88 & 91 & 76 & 100 & 102 & 101 & 82 & 92 & 83 & 105 & 87 & 84 & 82 & 112 & & & & & & & 1,373 \\
\hline 2003 & 127 & 135 & 152 & 140 & 139 & 143 & 81 & 82 & 88 & 72 & 94 & 97 & 97 & 81 & 87 & 77 & 99 & 85 & 81 & 76 & 106 & & & & & & 2,139 \\
\hline 2004 & & 106 & 113 & 134 & 119 & 124 & 128 & 77 & 79 & 85 & 71 & 90 & 94 & 95 & 76 & 85 & 70 & 95 & 82 & 79 & 76 & 102 & & & & & 1,980 \\
\hline 2005 & & & 94 & 107 & 126 & 111 & 119 & 117 & 75 & 72 & 78 & 67 & 84 & 90 & 93 & 71 & 84 & 68 & 92 & 78 & 75 & 70 & 99 & & & & 1,870 \\
\hline 2006 & & & & 87 & 99 & 116 & 98 & 113 & 108 & 73 & 65 & 75 & 65 & 82 & 85 & 88 & 69 & 82 & 68 & 91 & 75 & 72 & 69 & 94 & & & 1,774 \\
\hline 2007 & & & & & 82 & 94 & 107 & 94 & 109 & 102 & 70 & 63 & 73 & 65 & 82 & $\underline{8} \underline{5}$ & 87 & 70 & 80 & 64 & 84 & 72 & 67 & 66 & 90 & & 1,706 \\
\hline 2008 & & & & & & 76 & 90 & 100 & 90 & 105 & 99 & 66 & 63 & 70 & 61 & $\overline{8} 2$ & 84 & 83 & 67 & 81 & 64 & 80 & 72 & 64 & 63 & 88 & 1,648 \\
\hline
\end{tabular}

WAVEA:

WAVE B:

WAVEC:

Post-EEOL cohorts are in dotted box. 
Table 1. List of Variables

\begin{tabular}{|c|c|c|c|c|c|}
\hline Variable Name & Source & $\begin{array}{l}\text { Time Point of } \\
\text { Measurement }\end{array}$ & Variable Description & \begin{tabular}{|c|}
$\begin{array}{c}\text { Education } \\
\text { Eq. }\end{array}$ \\
\end{tabular} & \begin{tabular}{|c}
$\begin{array}{c}\text { Marriage } \\
\text { Eq. }\end{array}$ \\
\end{tabular} \\
\hline Completed education & JPSC & The initial survey year* & $\begin{array}{l}\text { University and above, } 1 \text {; junior college and } \\
\text { below, } 0 \text {. }\end{array}$ & Yes & Yes \\
\hline Marital status & JPSC & At the age of thirty-two & Ever married, $1 ;$ never married, 0 . & No & Yes \\
\hline Parents' income & JPSC & The initial survey year* & $\begin{array}{l}\text { Parents income in the previous year--5 dummy } \\
\text { variables with "low income" as the reference } \\
\text { category. } \\
\text { High income: above } 10 \text { million yen per year, } 1 \text {; } \\
\text { otherwise, } 0 \text {. } \\
\text { Middle income: between } 2.5 \text { million and } 10 \\
\text { million yen per year, } 1 \text {; otherwise, } 0 \text {. } \\
\text { Low income: below } 2.5 \text { million yen, } 1\end{array}$ & Yes & Yes \\
\hline Mother's education & JPSC & The initial survey year* & 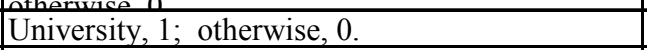 & Yes & No \\
\hline Father's education & JPSC & The initial survey year* & University, 1 ; otherwise, 0. & Yes & No \\
\hline Private high school & JPSC & The initial survey year* & Attended private high school, 1 ; otherwise, 0. & Yes & No \\
\hline Homemaker & JPSC & The initial survey year* & $\begin{array}{l}\text { During daughter's childhood (birth to age } 20 \text { ), } \\
\text { mother was never employed for pay, } 1 \text {; during } \\
\text { daughter's childhood, mother was at some point } \\
\text { employed for pay, } 0 \text {. }\end{array}$ & Yes & Yes \\
\hline Number of siblings & JPSC & The initial survey year* & Number of siblings & Yes & Yes \\
\hline Having brother(s) & JPSC & The initial survey year* & Has one or more brothers, 1 ; otherwise, 0 . & Yes & Yes \\
\hline Juku 2, Juku 3, Juku 4 & JPSC & The initial survey year* & $\begin{array}{l}\text { Juku 2: attended juku in the late years of } \\
\text { elementary school, } 1 \text {; otherwise, } 0 \text {. } \\
\text { Juku 3: attended juku when in junior high school, } \\
1 ; \text { otherwise, } 0 \text {. } \\
\text { Juku 4: attended juku when in high school, } 1 \text {; } \\
\text { otherwise } 0\end{array}$ & Yes & No \\
\hline Districts $1-10$ & JPSC & The initial survey year* & $\begin{array}{l}\text { District the respondent was living in when a } \\
\text { child--9 dummy variables with District } 1 \text { as the } \\
\text { reference district: } \\
\text { 1) Hokkaido, 2) Tohoku, 3) Southern-Kanto, 4) } \\
\text { Northern-Kanto \& Koshin, 5) Hokuriku, 6) } \\
\text { Tokai, 7) Kinki, 8) Chugoku, 9) Shikoku, 10) } \\
\text { Kunshw }\end{array}$ & Yes & Yes \\
\hline
\end{tabular}




\begin{tabular}{|c|c|c|c|c|c|}
\hline Large city & JPSC & $\begin{array}{l}\text { The initial survey } \\
\text { year* }\end{array}$ & $\begin{array}{l}\text { Living in Tokyo's } 23 \text { wards or in one of the } \\
\text { other } 13 \text { major Japanese cities, } 1 \text {; otherwise, } \\
0 . \quad \text { (Te reference category for the two city- } \\
\text { size variables is "towns, villages or overseas".) }\end{array}$ & No & Yes \\
\hline Medium city & JPSC & $\begin{array}{l}\text { The initial survey } \\
\text { year* }\end{array}$ & $\begin{array}{l}\text { Living in cities other than "large" cities, } 1 \text {; } \\
\text { otherwise, } 0 .\end{array}$ & No & Yes \\
\hline EEOA & JPSC & & $\begin{array}{l}\text { Those who were } 17 \text { or younger in } 1985 \text { (the } \\
\text { year the EEO Law was passed), 1; otherwise; } \\
0\end{array}$ & Yes & Yes \\
\hline Trend (Cohort trend) & JPSC & - & $\begin{array}{l}\text { Those who were born in } 1959 \text { (the oldest } \\
\text { respondents) were coded at } 1 \text {, and so on up to } \\
\text { those who were born in } 1979 \text { (the youngest } \\
\text { respondents), who were coded at } 21 .\end{array}$ & Yes & Yes \\
\hline Number of professors** & \begin{tabular}{|l|} 
Basic School Survey \\
(Ministry of Education, \\
Culture, Sports, Science and \\
Technology) \\
\end{tabular} & $\begin{array}{l}\text { At the age of } \\
\text { seventeen }\end{array}$ & Number of professors per high school graduate & Yes & No \\
\hline Spouse availability** & $\begin{array}{l}\text { Basic School Survey } \\
\text { (Ministry of Education, } \\
\text { Culture, Sports, Science and } \\
\text { Technology) }\end{array}$ & $\begin{array}{l}\text { At the age of } \\
\text { seventeen }\end{array}$ & $\begin{array}{l}\text { For respondents who did not have a university } \\
\text { degree: the ratio of (two-years senior) male } \\
\text { high school graduates to female high school } \\
\text { graduates who did not go to university. For the } \\
\text { respondents who have a university degree: the } \\
\text { ratio of (two-years senior) male high school } \\
\text { graduates who went to university to female } \\
\text { high school graduates who went to university. }\end{array}$ & No & Yes \\
\hline Vacancy/application $\quad \mathrm{ED} * *$ & $\begin{array}{l}\text { Job/employment placement } \\
\text { services statistics (Ministry } \\
\text { of Health, Labour and } \\
\text { Welfare) }\end{array}$ & $\begin{array}{l}\text { At the age of } \\
\text { seventeen }\end{array}$ & Ratio of job offers to job seekers & Yes & No \\
\hline Vacancy/application $\mathrm{MA}^{* *}$ & $\begin{array}{l}\text { Job/employment placement } \\
\text { services statistics (Ministry } \\
\text { of Health, Labour and } \\
\text { Welfare) }\end{array}$ & $\begin{array}{l}\text { At the age of } \\
\text { completing education\# }\end{array}$ & Ratio of job offers to job seekers & No & Yes \\
\hline University/high-school first wage ratio & $\begin{array}{l}\text { Basic Survey on Wage } \\
\text { Structure (Ministry of } \\
\text { Health, Labour and Welfare) }\end{array}$ & $\begin{array}{l}\text { At the age of } \\
\text { seventeen }\end{array}$ & $\begin{array}{l}\text { Ratio of university graduate's first wage to high } \\
\text { school graduate's first wage for males (national } \\
\text { average) }\end{array}$ & Yes & No \\
\hline Rent** & $\begin{array}{l}\text { Housing and Land Survey of } \\
\text { Japan (Statistics Bureau, } \\
\text { Ministry of Internal Affairs } \\
\text { and Communications) }\end{array}$ & $\begin{array}{l}\text { At the age of } \\
\text { completing education\# }\end{array}$ & $\begin{array}{l}\text { Real rent per tatami mat, in thousands of yen (a } \\
\text { tatami mat is approximately } 1.7 \text { square meters). }\end{array}$ & No & Yes \\
\hline
\end{tabular}

* The JPSC has four different survey waves. The initial survey year is 1993 for Wave A, 1997 for Wave B, 2003 for Wave C, and 2008 for Wave D.

$* *$ indicates that a not-JPSC variable is aggregated at prefecture level.

\# The age at which education is completed is assumed to be 18 for high school graduates, 21 for junior college or vocational school graduates, and 23 for university 
Table 2: Summary Statistics

\begin{tabular}{|c|c|c|c|c|}
\hline & Mean & Std. Dev. & Min & Max \\
\hline Marital Status & 0.8401 & 0.3666 & 0 & 1 \\
\hline Completed Education & 0.1690 & 0.3748 & 0 & 1 \\
\hline Large City & 0.2587 & 0.4380 & 0 & 1 \\
\hline Middle City & 0.5712 & 0.4950 & 0 & 1 \\
\hline Rent & 2.2323 & 0.9384 & 0.97 & 4.78 \\
\hline Spouse availability & 1.4686 & 0.4620 & 0.44 & 2.78 \\
\hline Vacancy/Applicants & 0.8464 & 0.4338 & 0.12 & 2.68 \\
\hline Middle Income Class & 0.5350 & 0.4989 & 0 & 1 \\
\hline High Income Class & 0.1613 & 0.3679 & 0 & 1 \\
\hline Mother's Education & 0.0400 & 0.1961 & 0 & 1 \\
\hline Father's Education & 0.1790 & 0.3834 & 0 & 1 \\
\hline Private High & 0.3045 & 0.4603 & 0 & 1 \\
\hline Homemaker & 0.3299 & 0.4703 & 0 & 1 \\
\hline Number of Siblings & 2.4707 & 0.9144 & 1 & 12 \\
\hline Having Brother(s) & 0.5804 & 0.4936 & 0 & 1 \\
\hline Juku 2 & 0.3714 & 0.4833 & 0 & 1 \\
\hline Juku 3 & 0.5889 & 0.4921 & 0 & 1 \\
\hline Juku 4 & 0.1821 & 0.3860 & 0 & 1 \\
\hline Number of Professors & 224.7074 & 93.9015 & 12 & 767 \\
\hline Vacancy/Application & 0.8751 & 0.4390 & 0.09 & 2.68 \\
\hline University/High-School First Wage Ratio & 1.2361 & 0.0365 & 1.15 & 1.42 \\
\hline EEOA & 0.5789 & 0.4938 & 0 & 1 \\
\hline $\mathrm{N}$ of obs. & 2,5 & & & \\
\hline
\end{tabular}


Table 3: Estimation Results: Bivariate Probit Model of Completed Education and Marital Status

\begin{tabular}{|c|c|c|c|c|c|c|}
\hline \multirow{3}{*}{ Education Equation } & \multicolumn{2}{|c|}{ (1) } & & \multicolumn{3}{|c|}{ (2) } \\
\hline & \multirow[t]{2}{*}{ Coef. } & \multicolumn{2}{|l|}{ S.E. } & \multirow[t]{2}{*}{ Coef. } & \multicolumn{2}{|l|}{ S.E. } \\
\hline & & & & & & \\
\hline EEOA & 0.1561 & 0.0792 & $* *$ & -0.0012 & 0.1301 & \\
\hline Trend & & & & 0.0154 & 0.0104 & \\
\hline Middle Income & 0.2157 & 0.0791 & $* * *$ & 0.2171 & 0.0791 & $* * *$ \\
\hline High Income & 0.4885 & 0.0985 & $* * *$ & 0.4874 & 0.0984 & $* * *$ \\
\hline Mother Education & 0.8781 & 0.1472 & $* * *$ & 0.8710 & 0.1475 & $* * *$ \\
\hline Father Education & 0.7274 & 0.0800 & $* * *$ & 0.7225 & 0.0802 & $* * *$ \\
\hline Private High & -0.1451 & 0.0721 & $* *$ & -0.1459 & 0.0721 & $* *$ \\
\hline Homemaker & 0.1493 & 0.0697 & $* *$ & 0.1571 & 0.0700 & $* *$ \\
\hline Sibling & -0.1254 & 0.0453 & $* * *$ & -0.1257 & 0.0453 & $* * *$ \\
\hline Brother & -0.0973 & 0.0722 & & -0.0961 & 0.0722 & \\
\hline Juku 2 & -0.0627 & 0.0702 & & -0.0636 & 0.0702 & \\
\hline Juku 3 & -0.1992 & 0.0728 & $* * *$ & -0.2109 & 0.0728 & $* * *$ \\
\hline Juku 4 & 0.7476 & 0.0787 & $* * *$ & 0.7510 & 0.0786 & $* * *$ \\
\hline Professor Ratio & -0.0003 & 0.0004 & & -0.0002 & 0.0004 & \\
\hline Vacancy/Applicant & -0.1596 & 0.0998 & & -0.1433 & 0.0999 & \\
\hline University/High-School First Wage Ratio & 0.3796 & 1.2423 & & 0.1828 & 1.2485 & \\
\hline constant & -1.8857 & 1.5602 & & -1.7440 & 1.5649 & \\
\hline \multicolumn{7}{|l|}{ Marriage Equation } \\
\hline Education & -0.3238 & 0.2808 & & -0.2760 & 0.2860 & \\
\hline EEOA & 0.0802 & 0.1004 & & 0.1678 & 0.1456 & \\
\hline Education $\times$ EEOA & -0.3556 & 0.1898 & $* * *$ & -0.3376 & 0.1917 & $*$ \\
\hline Trend & & & & -0.0117 & 0.0129 & \\
\hline Middle Income Class & -0.0130 & 0.0773 & & -0.0111 & 0.0773 & \\
\hline High Income Class & -0.0495 & 0.1163 & & -0.0507 & 0.1159 & \\
\hline Homemaker & -0.0806 & 0.0728 & & -0.0846 & 0.0729 & \\
\hline Siblings & 0.1662 & 0.0470 & $* * *$ & 0.1668 & 0.0471 & $* * *$ \\
\hline Brothers & -0.1430 & 0.0727 & $* *$ & -0.1443 & 0.0728 & $* *$ \\
\hline Large City & -0.2177 & 0.1148 & $*$ & -0.2206 & 0.1146 & $*$ \\
\hline Middle City & -0.1770 & 0.1005 & $*$ & -0.1769 & 0.1004 & $*$ \\
\hline Rent & -0.1782 & 0.0803 & $* *$ & -0.1662 & 0.0816 & $* *$ \\
\hline Spouse availability & -0.1354 & 0.1462 & & -0.0728 & 0.1674 & \\
\hline Vacancy/Applicants & -0.3272 & 0.1005 & $* * *$ & -0.3348 & 0.1011 & $* * *$ \\
\hline constant & 1.4021 & 0.2849 & $* * *$ & 1.3793 & 0.2891 & $* * *$ \\
\hline$\rho$ & 0.0078 & 0.1318 & & 0.0074 & 0.1306 & \\
\hline $\mathrm{N}$ of obs. & 25 & & & 25 & & \\
\hline Log Likelihood & -1840 & 758 & & -1835 & 309 & \\
\hline
\end{tabular}

Note: $* * *<1 \%, * *<5 \%, *<10 \%$. All equations are including district dummies. 
Table 4: Partial Effects on Education and Marriage Decisions

Panel A

\begin{tabular}{|c|c|c|c|c|c|c|c|c|c|}
\hline & \multicolumn{2}{|c|}{ Direct Effect } & & \multicolumn{2}{|c|}{ Indirect Effect } & \multicolumn{4}{|c|}{ Total Effect } \\
\hline & Estimate & Std. Err. & & Estimate & Std. Err. & & Estimate & Std. Err. & \\
\hline \multicolumn{10}{|l|}{ Education Decision } \\
\hline $\begin{array}{l}\text { EEOA } \\
\text { Middle Income }\end{array}$ & $\begin{array}{l}0.0309 \\
0.0403\end{array}$ & $\begin{array}{l}0.0141 \\
0.0116\end{array}$ & $\begin{array}{l}* * \\
* * *\end{array}$ & & & & & & \\
\hline High Income & 0.1029 & 0.0222 & $* * *$ & & & & & & \\
\hline Mother's Education & 0.2387 & 0.0488 & $* * *$ & & & & & & \\
\hline Father's Education & 0.1831 & 0.0228 & $* * *$ & & & & & & \\
\hline Private High & -0.0282 & 0.0154 & $* *$ & & & & & & \\
\hline Homemaker & 0.0305 & 0.0143 & $* *$ & & & & & & \\
\hline Number of Siblings & -0.0250 & 0.0097 & $* * *$ & & & & & & \\
\hline Having Brother(s) & -0.0195 & 0.0160 & & & & & & & \\
\hline Juku 2 & -0.0124 & 0.0157 & & & & & & & \\
\hline Juku 3 & -0.0402 & 0.0170 & $* *$ & & & & & & \\
\hline Juku 4 & 0.1864 & 0.0230 & $* * *$ & & & & & & \\
\hline Number of Professors & -0.0001 & 0.0001 & & & & & & & \\
\hline Vacancy/Application & -0.0318 & 0.0191 & $*$ & & & & & & \\
\hline University/High-school First Wage Ratio & 0.0757 & 0.2626 & & & & & & & \\
\hline \multicolumn{10}{|l|}{ Marriage Decision } \\
\hline Completed Education & -0.1496 & 0.0844 & $* *$ & & & & & & \\
\hline EEOA & 0.0058 & 0.0240 & & -0.0048 & 0.0029 & $*$ & 0.0010 & 0.0236 & \\
\hline Middle Income Class & -0.0030 & 0.0168 & & -0.0063 & 0.0037 & $*$ & -0.0094 & 0.0171 & \\
\hline High Income Class & -0.0117 & 0.0291 & & -0.0161 & 0.0088 & $*$ & -0.0278 & 0.0274 & \\
\hline Homemaker & -0.0191 & 0.0179 & & -0.0048 & 0.0029 & $*$ & -0.0240 & 0.0175 & \\
\hline Number of Siblings & 0.0389 & 0.0102 & $* * *$ & 0.0040 & 0.0025 & & 0.0429 & 0.0101 & $* * *$ \\
\hline Having Brother(s) & -0.0331 & 0.0164 & $* *$ & 0.0031 & 0.0030 & & -0.0300 & 0.0164 & $*$ \\
\hline Large City & -0.0487 & 0.0289 & $*$ & & & & & & \\
\hline Middle City & -0.0389 & 0.0230 & $*$ & & & & & & \\
\hline Rent & -0.0418 & 0.0188 & $* *$ & & & & & & \\
\hline Spouse availability & -0.0317 & 0.0360 & & & & & & & \\
\hline Vacancy/Applicants & -0.0766 & 0.0250 & $* * *$ & & & & & & \\
\hline Mother's Education & & & & -0.0368 & 0.0193 & $*$ & & & \\
\hline Father's Education & & & & -0.0284 & 0.0153 & $*$ & & & \\
\hline Private High School & & & & 0.0045 & 0.0035 & & & & \\
\hline Juku 2 & & & & 0.0020 & 0.0026 & & & & \\
\hline Juku 3 & & & & 0.0064 & 0.0049 & & & & \\
\hline Juku 4 & & & & -0.0288 & 0.0156 & $*$ & & & \\
\hline Number of Professors & & & & 0.0000 & 0.0000 & & & & \\
\hline Vacancy/Application & & & & 0.0050 & 0.0037 & & & & \\
\hline University/High-school First Wage Ratio & & & & -0.0120 & 0.0428 & & & & \\
\hline
\end{tabular}

Note: $* * *<1 \%, * *<5 \%, *<10 \%$. 
Table 4: Continued

Panel B

\begin{tabular}{|c|c|c|c|c|c|c|c|c|c|}
\hline & \multicolumn{2}{|c|}{ Direct Effect } & & \multicolumn{2}{|c|}{ Indirect Effect } & \multicolumn{4}{|c|}{ Total Effect } \\
\hline & Estimate & Std. Err. & & Estimate & Std. Err. & & Estimate & Std. Err. & \\
\hline \multicolumn{10}{|l|}{ Education Decision } \\
\hline EEOA & -0.0002 & 0.0251 & & & & & & & \\
\hline Trend & 0.0031 & 0.0023 & & & & & & & \\
\hline Middle Income & 0.0405 & 0.0116 & $* * *$ & & & & & & \\
\hline High Income & 0.1024 & 0.0221 & $* * *$ & & & & & & \\
\hline Mother's Education & 0.2360 & 0.0484 & $* * *$ & & & & & & \\
\hline Father's Education & 0.1814 & 0.0225 & $* * *$ & & & & & & \\
\hline Private High & -0.0283 & 0.0155 & $*$ & & & & & & \\
\hline Homemaker & 0.0321 & 0.0142 & $* *$ & & & & & & \\
\hline Number of Sibling(s) & -0.0250 & 0.0097 & $* *$ & & & & & & \\
\hline Having Brother(s) & -0.0192 & 0.0161 & & & & & & & \\
\hline Juku 2 & -0.0126 & 0.0156 & & & & & & & \\
\hline Juku 3 & -0.0425 & 0.0174 & $* *$ & & & & & & \\
\hline Juku 4 & 0.1871 & 0.0230 & $* * *$ & & & & & & \\
\hline Number of Professors & 0.0000 & 0.0001 & & & & & & & \\
\hline Vacancy/Application & -0.0285 & 0.0195 & & & & & & & \\
\hline University/High-school First Wage Ratio & 0.0364 & 0.2678 & & & & & & & \\
\hline \multicolumn{10}{|l|}{ Marriage Decision } \\
\hline Education & -0.1321 & 0.0841 & & & & & & & \\
\hline EEOA & 0.0277 & 0.0374 & & 0.0000 & 0.0038 & & 0.0277 & 0.0375 & \\
\hline TREND & -0.0028 & 0.0031 & & -0.0004 & 0.0004 & & -0.0032 & 0.0031 & \\
\hline Middle Income Class & -0.0026 & 0.0168 & & -0.0057 & 0.0037 & & -0.0083 & 0.0171 & \\
\hline High Income Class & -0.0120 & 0.0290 & & -0.0142 & 0.0091 & & -0.0263 & 0.0274 & \\
\hline Homemaker & -0.0202 & 0.0403 & & -0.0045 & 0.0029 & & -0.0247 & 0.0174 & \\
\hline Number of Siblings & 0.0392 & 0.0103 & $* * *$ & 0.0035 & 0.0025 & & 0.0428 & 0.0101 & $* * *$ \\
\hline Having Brother(s) & -0.0336 & 0.0164 & $* *$ & 0.0027 & 0.0028 & & -0.0309 & 0.0164 & $* *$ \\
\hline Large City & -0.0496 & 0.0290 & $*$ & & & & & & \\
\hline Middle City & -0.0389 & 0.0230 & $*$ & & & & & & \\
\hline Rent & -0.0391 & 0.0195 & $* *$ & & & & & & \\
\hline Spouse availability & -0.0171 & 0.0403 & & & & & & & \\
\hline Vacancy/Application & -0.0787 & 0.0253 & $* * *$ & & & & & & \\
\hline Mother's Education & & & & -0.0322 & 0.0191 & $*$ & & & \\
\hline Father's Education & & & & -0.0249 & 0.0154 & & & & \\
\hline Private High & & & & 0.0040 & 0.0034 & & & & \\
\hline Juku 2 & & & & 0.0018 & 0.0024 & & & & \\
\hline Juku 3 & & & & 0.0060 & 0.0050 & & & & \\
\hline Juku 4 & & & & -0.0257 & 0.0157 & & & & \\
\hline Number of Professors & & & & 0.0000 & 0.0000 & & & & \\
\hline Vacancy/Application & & & & 0.0040 & 0.0036 & & & & \\
\hline University/High-school First Wage Ratio & & & & -0.0051 & 0.0399 & & & & \\
\hline
\end{tabular}

Note: $* * *<1 \%, * *<5 \%, *<10 \%$. 